\title{
THE CO-AUTHORSHIP AND SUBJECT AREAS NETWORK IN MOOCS' SCIENTIFIC PRODUCTION IN WEB OF SCIENCE
}

\author{
Dr. Shadi ASADZANDI \\ ORCID: 0000-0002-1350-9629 \\ Virtual School \\ Tehran University of Medical Sciences \\ Tehran, IRAN \\ Dr. Rita MOJTAHEDZADEH \\ ORCID: 0000-0003-4560-6973 \\ Department of e-Learning in Medical Education \\ Virtual School, Tehran University of Medical Sciences \\ Tehran, IRAN \\ Dr. Aeen MOHAMMADI \\ ORCID: 0000-0002-2745-3873 \\ Department of e-Learning in Medical Education \\ Virtual School, Tehran University of Medical Sciences \\ Tehran, IRAN \\ Shiva MALGARD \\ ORCID: 0000-0002-2544-3313 \\ Management Faculty \\ Iran University of Medical Sciences \\ Tehran, IRAN \\ Hamed RASHIDI \\ ORCID: 0000-0001-6256-9874 \\ English Language and Literature \\ University of Tehran \\ Tehran, IRAN
}

Received: 03/11//2018 Accepted: 12/06/2019

\begin{abstract}
Massive Open Online Courses (MOOCs) is a new phenomenon in online learning which are held by higher education institutions and universities. MOOCs is larger than normal classes and it is free as well. The present study aims to specify the authors' structure of co-authorship and the required indicators in analyzing co-authorship, co-authorship network of countries, organizations and subject areas in MOOCs. All productions regarding scientific areas of MOOCs were extracted from the Web of Science from the beginning till 2016. There are 2195 extracted documents that were saved as txt and isi formats. Co-authorship drawing networks were prepared by website software CiteSpace version 5.1.R8 SE and Gephi version 0.9.2. MOOCs co-authorship network is regarded as spare that means the number of ties is less than nodes. This indicates that authors in this area have fewer tendencies for scientific relations. European countries play the main role in this area and their co-authorship is considerable. Harvard University has considerable co-authorship in this domain. According to the results of this study, MOOCs' network suffers from the lack of collaboration.
\end{abstract}

Keywords: Co-authorship, MOOCs, scientific production, Web of Science. 


\section{INTRODUCTION}

Massive Open Online Courses is a new phenomenon that is of great concern for university students, teachers, universities and institutions recently. However, this concept was emerged due to not only creating learning opportunities but improving the learning experience in 2008 (Gaebel, 2014; Gusti Salamah \& Alayham Abbas Helmi, 2018; Shafiq, Wani, Mahajan, \& Qadri, 2017). Stanford, Princeton and Pennsylvania universities have used this phenomenon with its today definition since 2011. The presence of these authoritative names and their efforts to provide knowledge with no charge and of course online have led to developing the concept of free massive online courses or MOOCs (Voss, 2013). To provide a definition on this new concept in teaching-learning, MOOCs is where free online courses are delivered mostly by universities with larger class size than normal. In addition MOOCs covers various subjects, and applies different teaching-learning methods (Liyanagunawardena, Adams, \& Williams, 2013; Mulder \& Jansen, 2015). In other words, MOOCs consists of four imperative terminologies that each resembles a significant feature. The term "Massive" points the great numbers of participants in an individual MOOC. The term "Open" refers to the free access to the courses. "Online" shows courses that are provided and accessed via internet, and at last, the term "Courses" means MOOCs resembles face to face classrooms' concepts and teaching methodologies, including evaluation tools (e.g. tests), providing feedback and issuing certificate, in order to provide learning experiences (Patru \& Balaji, 2016). There are some reasons raised for MOOCs' acceptance in the literature, some of which are education cost, efficient use of existing resources (e.g. blending traditional classes with MOOCs), providing new learning opportunities for traditional students, reaching new learners' groups and possibility of developing oneself as well as enhancing discernibility (Gusti Salamah \& Alayham Abbas Helmi, 2018).

Scientific collaboration is a key mechanism that connects the knowledge and efforts generalized to new ideas and main paths of research (Heinze \& Kuhlmann, 2008). In other words, it is the cooperation of the researchers together for reaching new knowledge (Katz \& Martin, 1997) or the connection of different talents for developing a new scientific case (Bu, Murray, Ding, Huang, \& Zhao, 2018; Kumar \& Jan, 2013; Misra, Smith-Doerr, Dasgupta, Weaver, \& Normanly, 2017). One way to scrutinize scientific collaboration is the study of co-authorship relations. Co-authorship is a process in which two or more authors share their talents and sources by adopting one of the cooperation methods and begin a collaboration to create a scientific work. One method that is used in probing the co-authorship collaboration is drawing co-authorship networks and its analysis (Koseoglu, Okumus, Putra, Yildiz, \& Dogan, 2018; Kumar, 2018; Sonnenwald, 2007).

Researchers use the same techniques that are used in analyzing social networks to study co-authorship networks. According to Wasserman and Faust this is defined as a collection of methods for analysis of social edifices within different parts of social environment. A co-authorship network displays the structure of knowledge (Koseoglu et al., 2018; Newman, 2004; Wasserman \& Faust, 1994). The network structures shows a variety of fascinating features of scientific societies (Wang, Wu, Pan, Ma, \& Rousseau, 2005) in which the indicators of social network analysis are used. There are various studies that use this method in analyzing co-authorship in different subject areas such as e-Learning in scopus database (Gupta \& Chohda, 2018), e-learning scientific domain (Tibana-Herrera, Fernandez-Bajon, \& de Moya-Anegon, 2018), collaboration rate of authors in e-Learning (Mohammadi, Asadzandi, \& Malgard, 2017), Zoology (Vimala \& Reddy, 2017), journals' level (Santos \& Santos, 2016), Korea and China co-authorship (Park, Yoon, \& Leydesdorff, 2016), Consumer Behavior Scholars (Neil Bendle, 2016), human immunodeficiency viruses (HIV) and Human papillomavirus (HPV) areas (Vanni et al., 2014), Evidence based Medicine (Shen et al., 2011), History and Philosophy (Osca-Lluch, Velasco, Lopez, \& Haba, 2009) and Bioinformatics (Malin \& Carley, 2007).

According to MOOCs' benefits and positive attitude of organizations and users towards this new phenomenon (Mulder \& Jansen, 2015; Voss, 2013), dealing with Scientometrics dimensions, especially drawing coauthorship networks and active subject areas, would provide researchers a vivid insight into related authors' activities and subject areas. So, the present study aims to specify the authors' structure of co-authorship; the required indicators in analyzing co-authorship; and co-authorship network of countries, organization and subject areas in MOOCs. The findings of this study affect the better understanding of identification of coauthorship dimensions in this milieu. Moreover, identifying the related influential authors and introducing them to the scientific society, provides the chance of further cooperation and collaboration. 


\section{METHODOLOGY}

\section{Participants}

This was an applied research with survey-descriptive design, regarding Scientometrics principles. We extracted publications related to scientific areas of MOOCs from the first ones till the end of 2016, from web of science on 8 August, 2017. We used the following searching formula: TS= ("MOOCs" OR "MOOC" OR "Massive open online learning" OR "Massive open online course*" OR "XMOOC" OR "CMOOC" OR "Massive education" OR "Massive learning" OR "open sources technology" or "free course"*” or "Open ware").

\section{Data Collection and Analysis}

Our search in web of science, reached to 2195 documents which were saved in txt and isi formats. Coauthorship networks were drawn by website software, CiteSpace version 5.1.R8 SE and Gephi version 0.9.2, that were free powerful illustrating networks (Bastian, Heymann, \& Jacomy, 2009). Firstly, the applied and appropriate thresholds along with the number of nodes were imported into the CiteSpace software. Threshold limits the number of network's nodes considering received citations, which leads to omitting weak relations. The considered threshold selected for this study is 3, 3 and 20 for number of citations, co-citations, and cosine co-efficient co-citation respectively. (Olmeda-Gomez, Perianes-Rodriguez, Antonia Ovalle-Perandones, Guerrero-Bote, \& de Moya Anegon, 2009).

Then, we imported the outputs of this software into Gephi for drawing the network. For this purpose, we selected the undirected network item and chose the Fruchterman and Force Atlas2 algorithms to draw the intended network. The selected co-authorship indicators were as follows:

- "Degree Centrality" is the easiest form of centrality in which the value of each node is obtained by counting the number of its neighbors. The higher the level of centrality of a person, the more relations and networks one possesses (Hariri \& Nikzad, 2011).

- "Betweenness Centrality" indicates the importance of node as well as information transfer within network point of view. Having Betweenness Centrality, shows being located among many other nodes through which other communication paths are passing (Hariri \& Nikzad, 2011).

- "Closeness Centrality" evaluates the position and the real distance of node with that of other nodes within the network (Braun, 2005).

- "Diameter" is the longest distance between a pair of network nodes. Also, the diameter shows the tendency of a network to have fewer relations (Clarke, 1964).

- "Density of network" is considered as a scale for calculating the density that shows the network's spare and density. So that, in a spare network, connections among the nodes are a few; on the other hand, in a dense network the number of lines or ties in one graph are more than vertices or nodes (Clarke, 1964).

- "Clustering coefficient" is an indicator which shows how much the nodes of a network tend to make cluster together. This means that how well a node connects to its surrounding nodes (Clarke, 1964).

- "Average Degree" is the overall ties' relations of each node to whole nodes. This shows the average number of nodes that are interconnected with one individual node (Keenan \& Cochrane, 1964).

All the above-mentioned indicators were calculated in this study. In addition, we identified MOOCs' active subject areas by retrieving and analyzing data with features of Web of Science and Excel 2010.

\section{FINDINGS}

In the drown MOOCs' co-authorship network, the overall numbers of nodes and relation were 119 and 110 respectively. Pics 1 to 4 show the network regarding four indicators of Degree Centrality, Betweenness, Closeness and Eigenvector. 


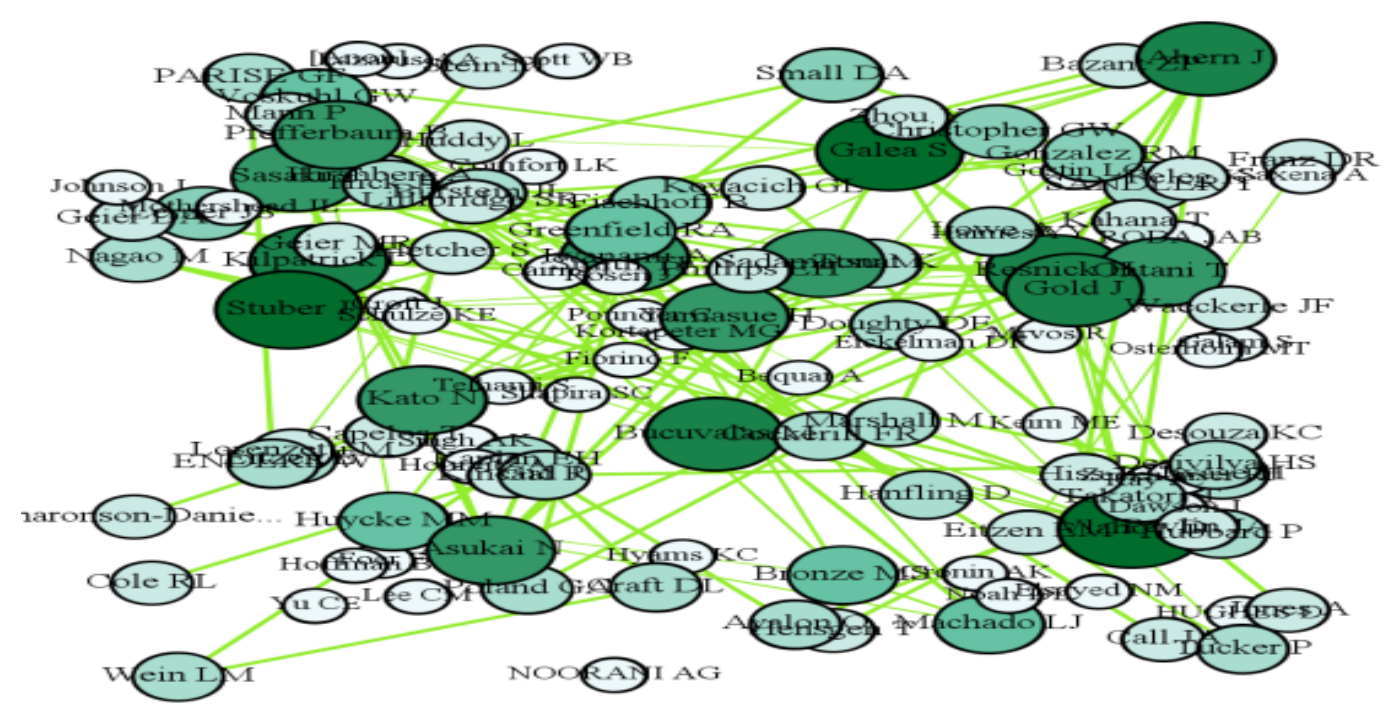

Figure 1. The co-authorship network of authors in MOOCs area according to Degree Centrality from the beginning till the end of 2016

Figure 1 demonstrates the authors' area network according to Degree Centrality. It shows that the larger a circle becomes, the more the Degree Centrality becomes as well. The value of each node depends on the number of its neighbors, so that with more number of connections, the Degree Centrality also increases. In the above picture Stuber, Vlahov and Galea have the highest degree centrality, which means that they have the largest number of neighbors and connections compared to others.

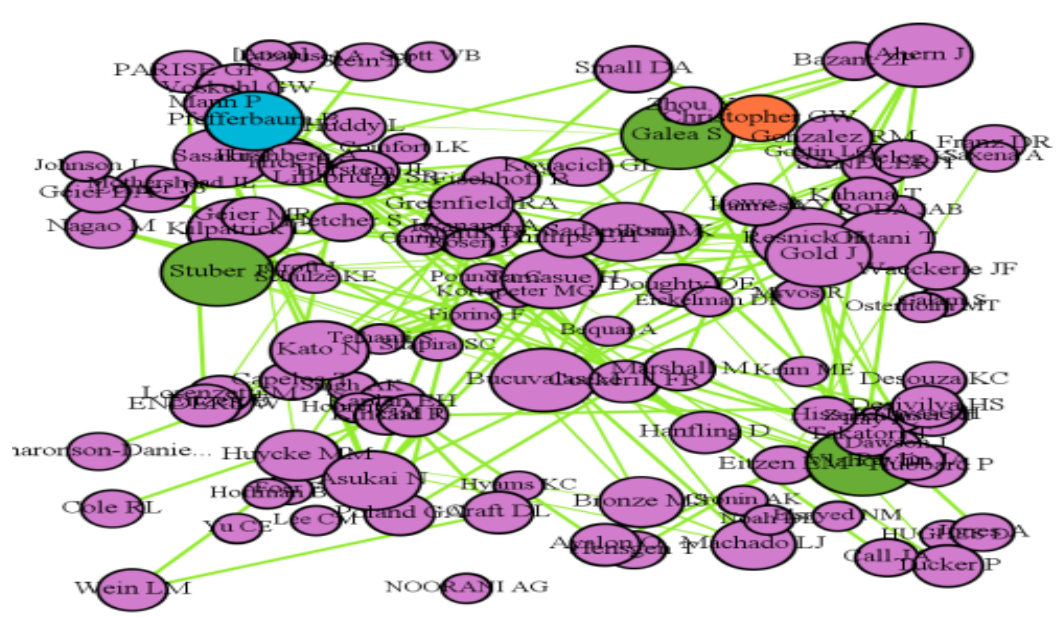

Figure 2. The co-authorship network of authors in MOOCs area according to Betweenness Centrality from the beginning till the end of 2016

In Figure 2, the circles which are colored other than purple designate a higher Betweenness Centrality. Pfefferbaum (blue node) has the highest Betweenness Centrality among researchers in MOOCs area. In other words, Pfefferbaum' node stands among many nodes and plays the role of intermediate connection among other nodes which leads to transferring information. If this node were omitted, the flow of information among other nodes would have been interrupted or the network would have been compromised. 


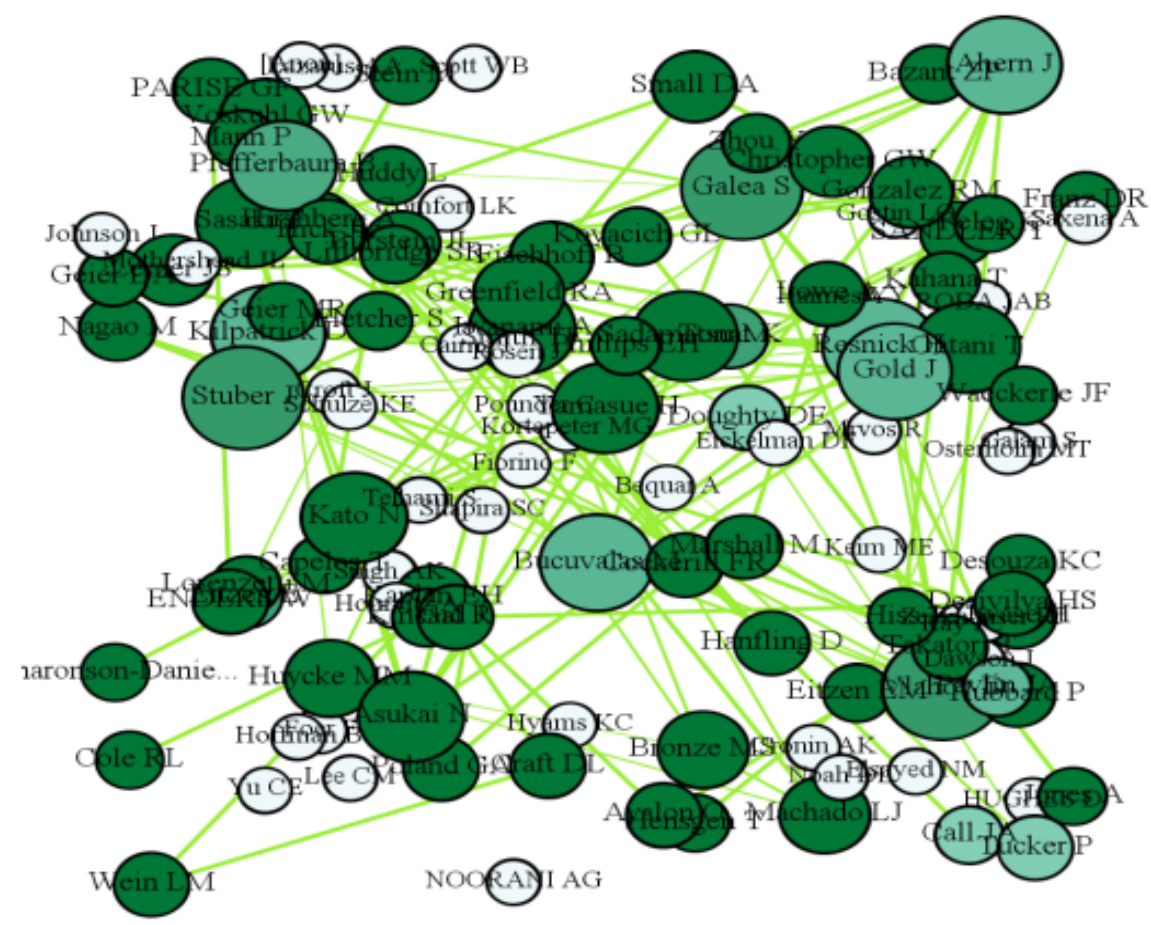

Figure 3. The co-authorship network of authors in MOOCs area according to Closeness Centrality from the beginning till the end of 2016

In Figure 3, the larger nodes show more Closeness Centrality. Sasaki, Iwanami and Yamasue have more Closeness Centrality, which means that there are fewer mediators when transferring information to them, so they get information faster than the other.

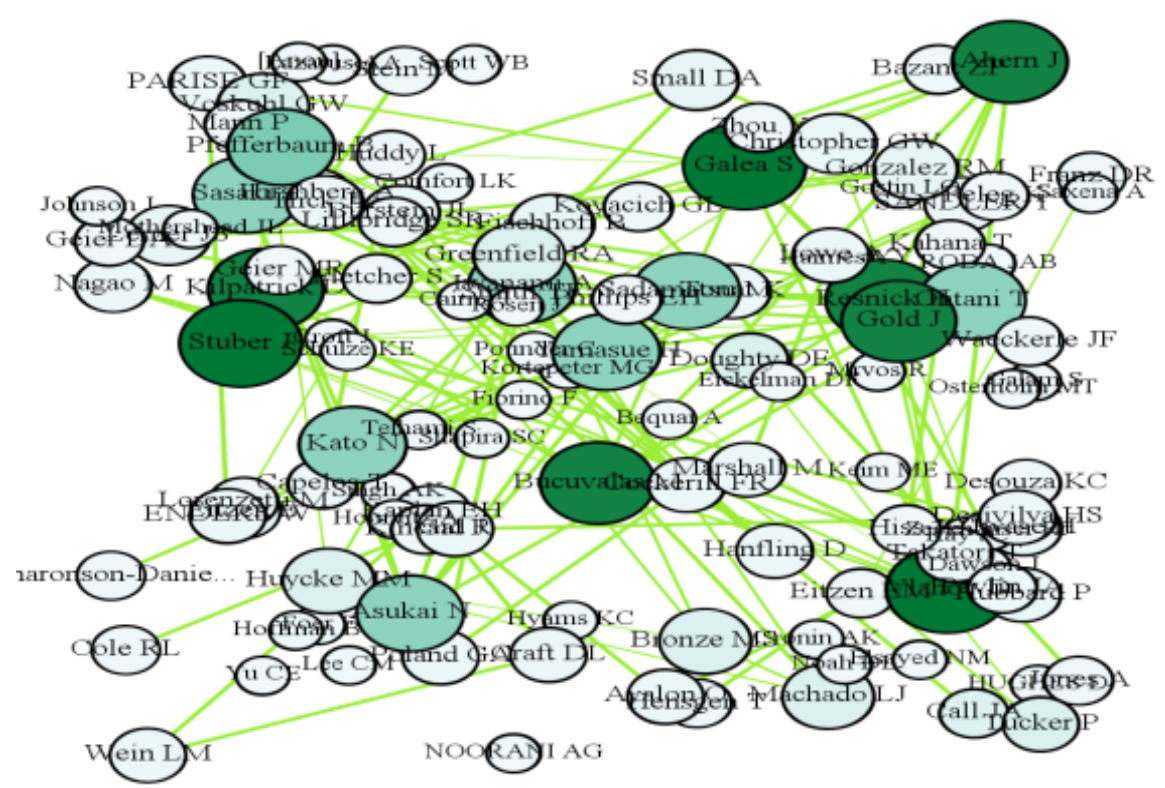

Figure 4. The co-authorship network of authors in MOOCs area according to Eigenvector Centrality from the beginning till the end of 2016 
Figure 4 indicates the Eigenvector Centrality. This indicator is higher in nodes which are larger. Kilpatrick and Bucuvalas have the largest nodes in this indicator. It means that these two authors are more connected to the major authors of the field. On the other hand, they play an important role in the MOOCs milieu at the moment.

In addition to above mentioned pictures, table 1 shows first rank-authors according to these indicators.

Table1. The centrality indicators for the first top authors in MOOCs area from the beginning till the end of 2016

\begin{tabular}{ccccccccc}
\hline Row & Author & $\begin{array}{c}\text { Degree } \\
\text { Centrality }\end{array}$ & Author & $\begin{array}{c}\text { Betweenness } \\
\text { Centrality }\end{array}$ & Author & $\begin{array}{c}\text { Closeness } \\
\text { Centrality }\end{array}$ & Author & $\begin{array}{c}\text { Eigenvector } \\
\text { Centrality }\end{array}$ \\
\hline 1 & Galea S & 8 & Pfefferbaum B & 26.0 & Iwanami A & 1 & Bucuvalas M & 1 \\
2 & Vlahov D & 8 & Galea S & 6.67 & Sasaki T & 1 & Kilpatrick D & 1 \\
3 & Stuber J & 8 & Vlahov D & 6.67 & Yamasue H & 1 & Resnick H & 1 \\
4 & Bucuvalas M & 7 & Stuber J & 6.67 & Sadamatsu M & 1 & Ahern J & 0.94 \\
5 & Kilpatrick D & 7 & Christopher GW & 2.0 & Ohtani T & 1 & Gold J & 0.91 \\
\hline
\end{tabular}

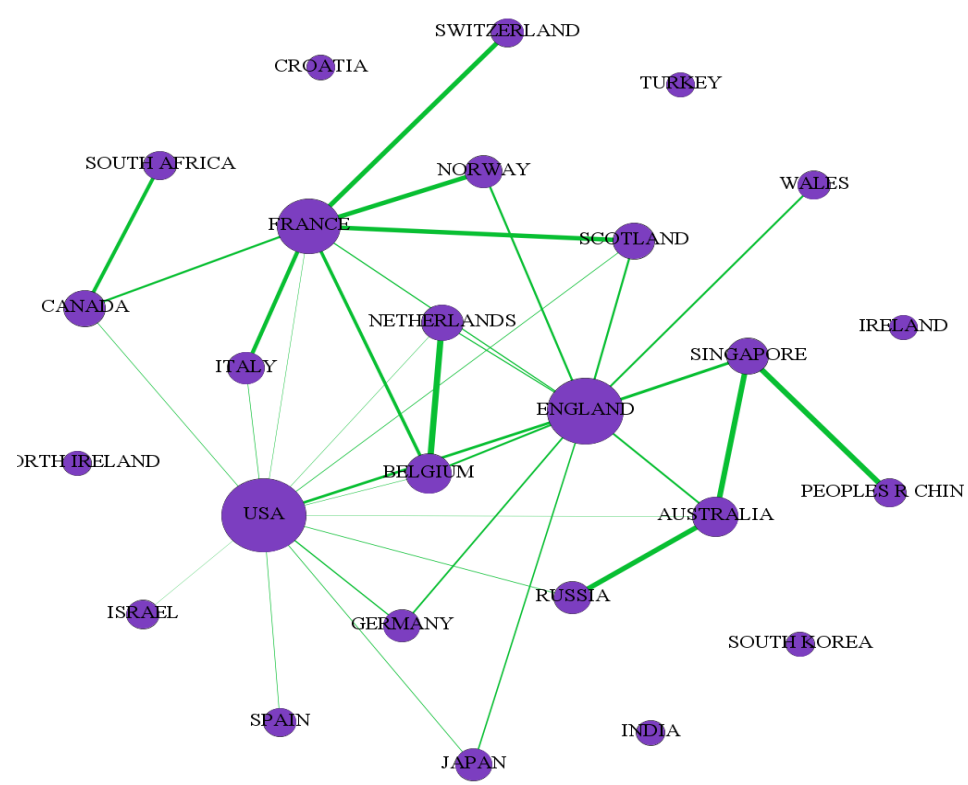

Figure 5. MOOCs co-authorship network according to the countries from the beginning till the end of 2016.

The co-authorship network according to the countries is shown in Figure 5. This network includes 26 nodes and 34 ties which is considered almost a dense network. In this network, United States and United Kingdom have the highest productions and connections with their neighbors. The tie' diameter for each country indicates its strength and weakness compared to others. Besides, while United Kingdom has made strong connections with several countries shown in co-authorship clusters, Finland and Belgium have made fewer connections. 


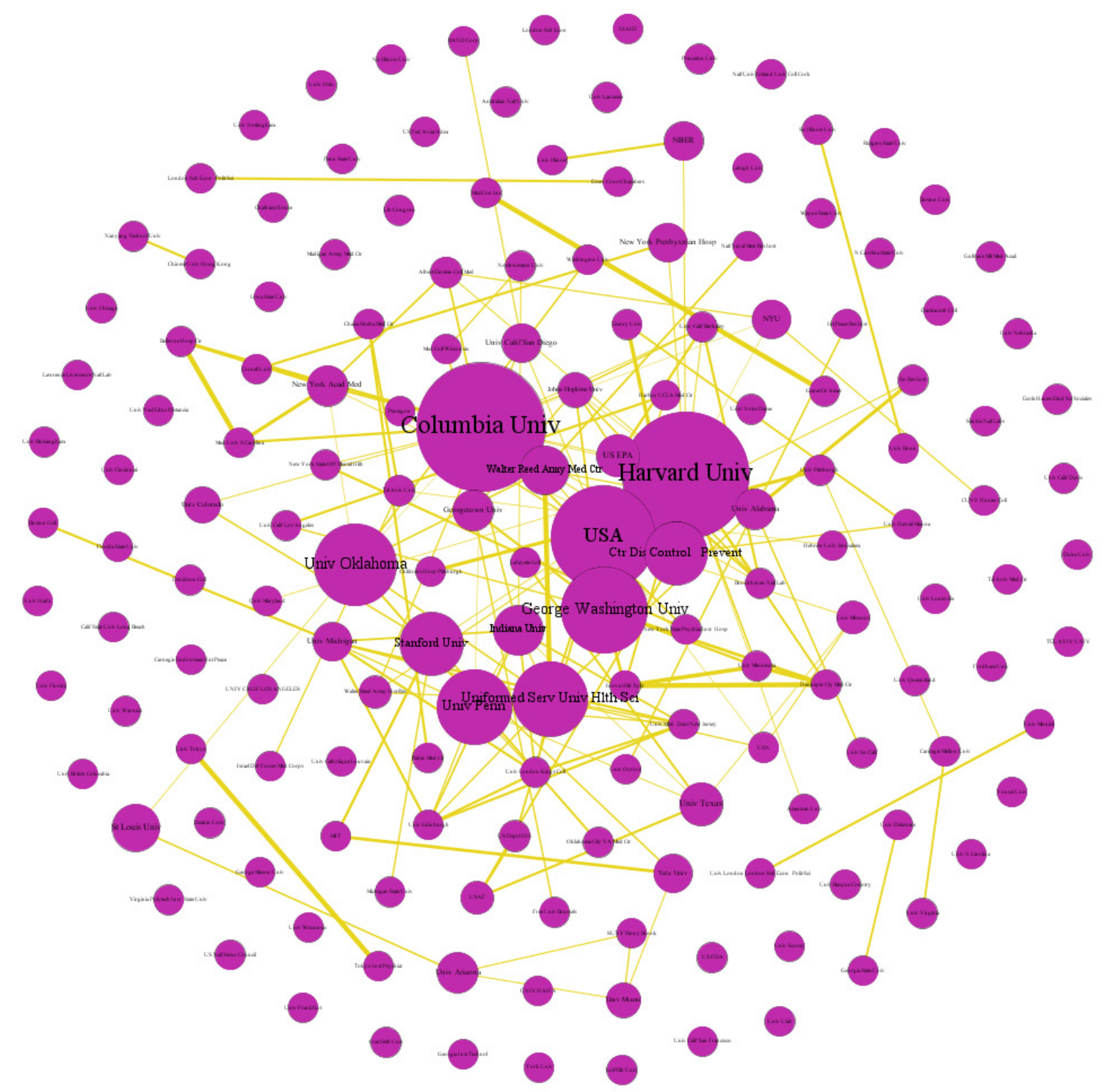

Figure 6. The MOOCs co-authorship network according to organizations from the beginning till the end of 2016

In Figure 6, the co-authorship network is drawn according to universities and institutions that are working in this area. This network includes 160 nodes and 151 connections which is a spare network. Colombia and Harvard universities have the highest Degree Centrality and have made strong connections with other institutions. In the marginal area of picture, there are universities and institutions that although are working in this area, they do not have any connections with other organizations. 


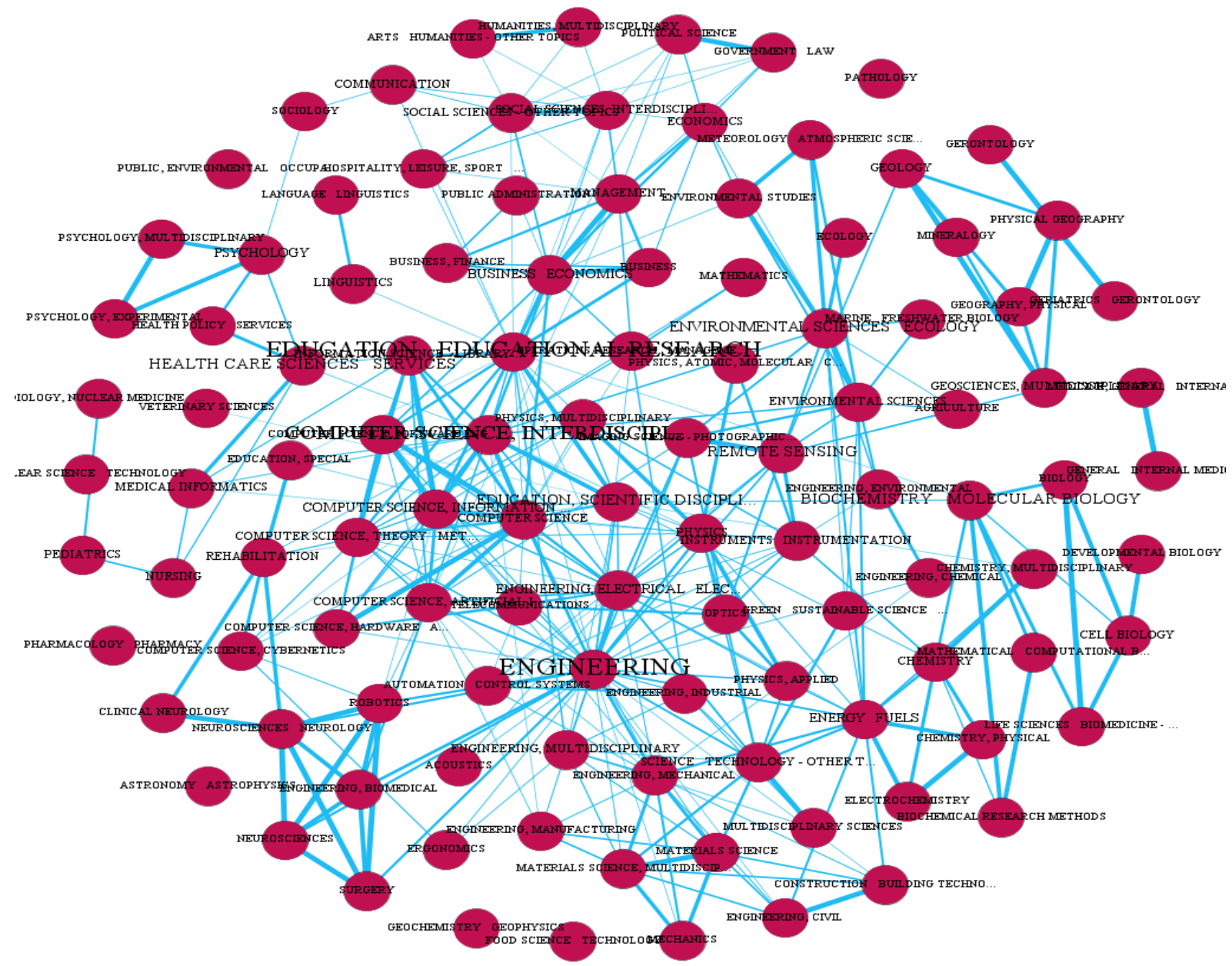

Figure 7. MOOCs' co-authorship network according to subject areas from the beginning till the end of 2016

In Figure 7, the co-authorship network is drawn for related subject areas. The numbers of nodes and connections of this network are 111 and 354, showing the density of this network. The nodes that have higher degree centrality are demonstrated with larger fonts. The Engineering, Education and Computer areas are with highest Degree Centrality, meaning that they have connections and clusters with other areas.

\section{DISCUSSIONS AND CONCLUSION}

MOOCs is a new concept that has been considered serious in the recent years. Besides, major universities and organizations support it. The analysis of the productions of this area in WOS indicates a rapid increase since 2013 reaching to 749 documents in 2016. Indeed, scientific production in the field of e-learning, as the closest area to MOOCs, has been increasing in recent years too (Mohammadi et al., 2017; TibanaHerrera et al., 2018). In this study, the MOOCs co-authorship networks were drawn according to different indicators from the beginning to the end of 2016. The network analysis showed that MOOCs co-authorship network was a spared one, with lesser number of ties than nodes. This would be interpreted as lesser tendency of authors in this area for scientific relations. Besides, calculating the network average degree showed that authors tended to connect to 2 to 4 researchers on average which could weaken this area. Owing to growth of science and emergence of interdisciplinary areas, it is difficult to conduct a research individually. In fact, by specializing in science, it is impossible for authors to be satisfactory specialized in all areas. Literature related to scientometrics in e-learning also indicates that authors tend to connect with 1 or 2 authors, which is not in concurrence with the nature of multidisciplinary disciplines; even though it is assumed that in any field of science, there must be a wide co-authorship network with numerus connections (Gupta \& Chohda, 2018; 
Tibana-Herrera et al., 2018). Indeed, scientific collaboration is introduced as one element for developing a field of science. Collaboration and sharing skills and ideas among authors, would positively affect the quality and quantity of productions in the field (De Stefano, Fuccella, Vitale, \& Zaccarin, 2013; Hara, Solomon, Kim, \& Sonnenwald, 2003; Osareh, Serati Shirazi, \& Khademi, 2014). Therefore, increasing collaboration and co-authorship is necessary in this area.

Another finding of this study showed that there were a few countries that played prominent role in MOOCs' co-authorship network. European countries were the ones that had a better co-authorship network. On the other hand, United States had the highest degree centrality and United Kingdom, France and Australia had made stronger connections among different countries. This was stated in some other literature reviews (Santos \& Santos, 2016; Tibana-Herrera et al., 2018).

Reviewing the co-authorship network of organizations showed that the centrality of some universities was clearly observable, i.e. these universities were the turning point in MOOCs area production. For example, Harvard university was one of the centers that had publications in MOOCs area since 2012 (Voss, 2013) and had been remaining as one of the most important universities with considerable co-authorship in this area. The number of connections in this network was lower than the nodes, indicating the weakness of coauthorship among these institutions, whereas universities and academic institutions must act more efficiently in scientific collaboration. When it came to degree centrality for various subject areas, but co-authorship and their connections are considerable. Fields such as Education, Engineering and Computer science that have highest degree centrality are placed the first in analyzing the distribution of documents in MOOCs comparing to other subject areas.

Finally, we reached to the point that MOOCs' co-authorship network lacks enough collaboration, meanwhile strong networks would lead to rapid growth of science and increase in productions (Osareh et al., 2014). So, adopting national and international policies for supporting team-working productions and interdisciplinary researches would improve tendencies for scientific collaboration.

Acknowledgements: This research is supported by Tehran University of Medical Sciences grant number 96-02-176-35662.

\section{BIODATA and CONTACT ADDRESSES of AUTHORS}

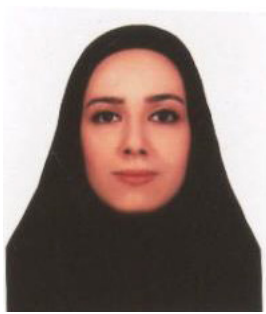

Dr. Shadi ASADZANDI, has a PhD degree in library and information science at Iran University of medical sciences. She has worked in virtual school of Tehran medical university (TUMS) since 2011. Her current field placement is with research department in Virtual school at Tums. She is skilled and passionate in gamification and educational game and also interested in e-learning.

Shadi ASADZANDI

Adress: Virtual school, Tehran University of medical sciences, Tehran, Iran

Phone: +9809120903147

Email: shadi_asadzandi@yahoo.com 


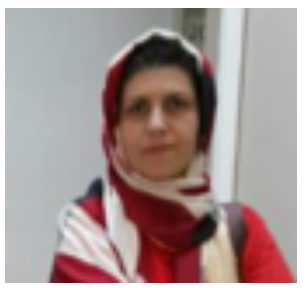

Dr. Rita MOJTAHEDZADEH, has PhD in E-learning Planning. She is one of the founders of Virtual School of TUMS and currently a faculty member of e-Learning in Medical Education Department in this school. She has been principal investigators of several developmental and research projects in the field of e-learning and medical education in Iran. Now she, as the core responsible body, is working on development and establishment of Iran's national Massive Open Online Courses (MOOCs) platform and national Learning Management System (LMS). Her fields of interest are: e-learning, instructional design, medical education, accreditation and ranking.

Rita MOJTAHEDZADEH

Adress: Department of e-Learning in Medical Education, Virtual School, Tehran University of Medical Sciences, Tehran, Iran

Phone: +9809126183193

Email: r_mojtahedzadeh@tums.ac.ir

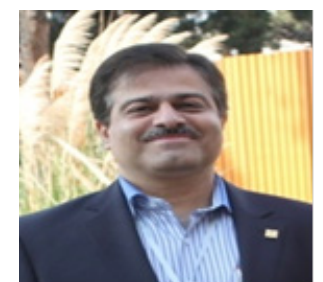

Dr. Aeen MOHAMMADI, has $\mathrm{PhD}$ in Medical Education. He is one of the founders of Virtual School of TUMS and currently a faculty member of e-Learning in Medical Education Department in this school. He has been principal investigator of several developmental and research projects in the field of e-learning and medical education in Iran, some of which are as follows: academic ranking of medical schools, stratification of educational services, designing and establishment of the measurement system of faculties' members' activities (metrics system), designing and installing the comprehensive educational award system. Now he, as the manager, is working on development and establishment of Iran's national Massive Open Online Courses (MOOCs) platform and national Learning Management System (LMS).

Aeen MOHAMMADI

Adress: Department of e-Learning in Medical Education, Virtual School, Tehran University of Medical Sciences, Tehran, Iran

Phone: +9809125262067

Email: aeen_mohammadi@tums.ac.ir

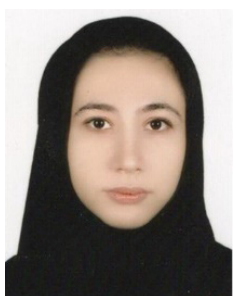

Shiva MALGARD, is PhD candidate in library and information science at Iran University of medical sciences. She is skilled in scientometrics studies. Her scientific interests include information retrieval, data mining, information management systems, health information management, ontology, scientometrics, altmetrics, web searching and editing.

Shiva MALGARD

Adress: Management faculty, Iran University of medical sciences Tehran, Iran Tel: +9809163352237

Email: sh_malgard@yahoo.com

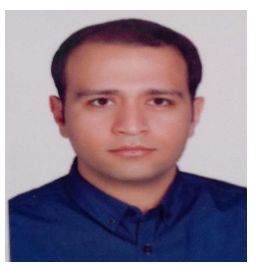

Hamed RASHIDI, graduated in Teaching English as a Foreign Language (TEFL) M.A from University of Tehran, Iran, with strong dedication to corpus studies that are intertwined with other disciplines. He has also done a lot of classroom observation focusing on Teaching/Learning issues regarding cooperation as well collaboration.

Hamed RASHIDI

Adress: English Language and Literature, University of Tehran. Tehran, Iran.

Tel: +9809126504553

Email: hamedrashidi@ut.ac.ir 


\section{REFERENCES}

Bastian, M., Heymann, S., \& Jacomy, M. (2009). Gephi: an open source software for exploring and manipulating networks. Icwsm, 8, 361-362.

Braun, T. (2005). Handbook of Quantitative Science and Technology Research. The Use of Publication and Patent Statistics in Studies of S\&t Systems. Scientometrics, 63(1), 185-188.

Bu, Y., Murray, D. S., Ding, Y., Huang, Y., \& Zhao, Y. (2018). Measuring the stability of scientific collaboration. Scientometrics, $114(2), 463-479$.

Clarke, B. L. (1964). Multiple authorship trends in scientific papers. Science, 143(3608), 822-824.

De Stefano, D., Fuccella, V., Vitale, M. P., \& Zaccarin, S. (2013). The use of different data sources in the analysis of co-authorship networks and scientific performance. Social Networks, 35(3), 370-381.

Gaebel, M. (2014). MOOCs: Massive open online courses: EUA.

Gupta, N., \& Chohda, N. (2018). Evinced E-Learning published research in scopus database from 20072016: The scientometric study. Gyankosh-The Journal of Library and Information Management, 9(1), 24-32.

Gusti Salamah, U., \& Alayham Abbas Helmi, R. (2018). MOOC Platforms: a Review and Comparison. International Journal of Engineering \& Technology, 7(4,11), 70-74.

Hara, N., Solomon, P., Kim, S. L., \& Sonnenwald, D. H. (2003). An emerging view of scientific collaboration: Scientists' perspectives on collaboration and factors that impact collaboration. Journal of the Association for Information Science and Technology, 54(10), 952-965.

Hariri, N., \& Nikzad, M. (2011). Co-authorship networks of Iranian articles in library and information science, psychology, management and economics in ISI during 2000-2009. Iranian journal of Information Processing \& Management, 26(4), 825-844.

Heinze, T., \& Kuhlmann, S. (2008). Across institutional boundaries?: Research collaboration in German public sector nanoscience. Research policy, 37(5), 888-899.

Katz, J. S., \& Martin, B. R. (1997). What is research collaboration? Research policy, 26(1), 1-18.

Keenan, S., \& Cochrane, P. A. (1964). The Journal Literature of Physics: A Comprehensive Study Based on Physics Abstracts: American Institute of Physics.

Koseoglu, M. A., Okumus, F., Putra, E. D., Yildiz, M., \& Dogan, I. C. (2018). Authorship trends, collaboration patterns, and co-authorship networks in lodging studies (1990-2016). Journal of Hospitality Marketing \& Management, 27(5), 561-582.

Kumar, S. (2018). Ethical Concerns in the Rise of Co-Authorship and Its Role as a Proxy of Research Collaborations. Publications, 6(3), 37.

Kumar, S., \& Jan, J. M. (2013). Mapping research collaborations in the business and management field in Malaysia, 1980-2010. Scientometrics, 97(3), 491-517.

Liyanagunawardena, T. R., Adams, A. A., \& Williams, S. A. (2013). MOOCs: A systematic study of the published literature 2008-2012. The International Review of Research in Open and Distributed Learning, 14(3), 202-227.

Malin, B., \& Carley, K. (2007). A longitudinal social network analysis of the editorial boards of medical informatics and bioinformatics journals. Journal of the American Medical Informatics Association, 14(3), 340-348.

Misra, J., Smith-Doerr, L., Dasgupta, N., Weaver, G., \& Normanly, J. (2017). Collaboration and gender equity among academic scientists. Social Sciences, 6(1), 25.

Mohammadi, A., Asadzandi, S., \& Malgard, S. (2017). A Survey of the Collaboration Rate of Authors in the E-Learning Subject Area over a 10-Year Period (2005-2014) Using Web of Science. The International Review of Research in Open and Distributed Learning, 18(2). 
Mulder, F., \& Jansen, D. (2015). MOOCs for opening up education and the OpenupEd initiative. MOOCs and Open Education around the world, 130-142.

Neil Bendle, X. S. W. a. F. M. (2016). Understanding Co-Authorship among

Consumer Behavior Scholars. Journal for Advancement of Marketing Education-, 24(1), 1-13.

Newman, M. E. (2004). Coauthorship networks and patterns of scientific collaboration. Proceedings of the national academy of sciences, 101 (suppl 1), 5200-5205.

Olmeda-Gomez, C., Perianes-Rodriguez, A., Antonia Ovalle-Perandones, M., Guerrero-Bote, V. P., \& de Moya Anegon, F. (2009). Visualization of scientific co-authorship in Spanish universities: From regionalization to internationalization. Paper presented at the Aslib Proceedings.

Osareh, F., Serati Shirazi, M., \& Khademi, R. (2014). A Survey on Co-authorship Network of Iranian Researchers in the field of Pharmacy and Pharmacology in Web of Science during 2000-2012. Journal of Health Administration, 17(56), 33-45.

Osca-Lluch, J., Velasco, E., Lopez, M., \& Haba, J. (2009). Co-authorship and citation networks in Spanish history of science research. Scientometrics, 80(2), 373-383.

Park, H. W., Yoon, J., \& Leydesdorff, L. (2016). The normalization of co-authorship networks in the bibliometric evaluation: the government stimulation programs of China and Korea. Scientometrics, 109(2), 1017-1036.

Patru, M., \& Balaji, V. (2016). Making sense of MOOCs: A Guide for policy-makers in developing countries Retrieved from http://unesdoc.unesco.org/images/0024/002451/245122E.pdf

Santos, J. A. C., \& Santos, M. C. (2016). Co-authorship networks: Collaborative research structures at the journal level. Tourism \& Management Studies, 12(1), 5-13.

Shafiq, H., Wani, Z. A., Mahajan, I. M., \& Qadri, U. (2017). Courses beyond borders: A case study of MOOC platform Coursera. Library Philosophy and Practice, 1-15.

Shen, J., Yao, L., Li, Y., Clarke, M., Gan, Q., Fan, Y., . . Wang, L. (2011). Visualization studies on evidencebased medicine domain knowledge (series 2): structural diagrams of author networks. Journal of Evidence-Based Medicine, 4(2), 85-95.

Sonnenwald, D. H. (2007). Scientific collaboration. Annual review of information science and technology, 41(1), 643-681.

Tibana-Herrera, G., Fernandez-Bajon, M. T., \& de Moya-Anegon, F. (2018). Global analysis of the E-learning scientific domain: a declining category? Scientometrics, 114(2), 675-685.

Vanni, T., Mesa-Frias, M., Sanchez-Garcia, R., Roesler, R., Schwartsmann, G., Goldani, M. Z., \& Foss, A. M. (2014). International scientific collaboration in HIV and HPV: a network analysis. PloS one, 9(3), e93376.

Vimala, V., \& Reddy, V. P. (2017). Authorship pattern and collaborative research in the field of zoology. Malaysian Journal of Library \& Information Science, 1(2), 43-50.

Voss, B. D. (2013). Massive open online courses (MOOCs): A primer for university and college board members. AGB Association of Governing Boards of Universities and Colleges.

Wang, Y., Wu, Y., Pan, Y., Ma, Z., \& Rousseau, R. (2005). Scientific collaboration in China as reflected in co-authorship. Scientometrics, 62(2), 183-198.

Wasserman, S., \& Faust, K. (1994). Social network analysis: Methods and applications (Vol. 8): Cambridge university press. 